\title{
Diagnostic Immunohistochemistry with Manual Tissue Microarray Technique: A Pilot Study on Non-Hodgkin Lymphoma
}

\author{
Kumudhini Priya Gunasekaran ${ }^{1}$ and Anbu Lenin Kulandaivel2* \\ 'Department of Pathology, Annapoorana Medical College and Hospitals, Salem - 636308, Tamil Nadu, India. \\ ${ }^{2}$ Department of Pathology, Vinayaka Mission's KirupanandaVariyar Medical College and Hospital, Salem - 636308, Tamil Nadu, India.
}

\section{ABSTRACT}

Background: Non Hodgkin lymphomas are clonal lymphoproliferative disorders that needs to be classified immunologically by variety of immunological markers targeted against specific antigens. Tissue microarrayallows for high-throughput molecular profiling of tissue specimens usingimmunohistochemistry resulting in reduced consumption of time and reagents as compared to conventional immunohistochemistry.

Method: This three-year single institutional observational study was conducted at Tirunelveli Medical College, Tirunelveli, Tamilnadu.21 cases ofhistopathologically diagnosed NHLwere subjected to Immunohistochemistry using manual Tissue microarray. Paraffin embedded tissue blocks of all the NHL cases formed donor blocks. Lay out for Tissue microarray was constructed followed by manual transfer of cored tissue from representative areas of donor blocks into recipient block using bone marrow needles. Immunohistochemistry was done using antibody against CD3,CD5, CD10 and CD20. Inadequate lymph node samples, poorly processed samples and extranodal NHL were excluded.

Result: Of total 21 cases subjected to immunohistochemistry using Tissue microarray technique, only 19 cases were taken for analysis due to tissue loss and histopathological misdiagnosis. Among 19 cases there were $11[57.89 \%]$ males and $8[42.11 \%]$ females with male to female ratio of 1.37:1. Mean age ofstudy group was54.7years. There were 18[94.73\%] cases of B-cell NHL with 1[5.27\%] case of T-cell NHL. DLBCL constituted for $9[47.36 \%]$ cases. Immunohistochemistry using Tissue microarray consumed $1 / 6$ th of the reagent volume as that of conventional immunohistochemistry.

Keywords: Non Hodgkin Lymphoma, Immunohistochemistry, Donor Block, Recipient Block, Tissue Microarray.

\section{Introduction}

Lymphoid neoplasms include a diverse group of tumors of B-cell, T-cell, and NK-cell origin. Lymphomas are ranked $6^{\text {th }}$ among all cancers, worldwide ${ }^{[1]}$. Non Hodgkin lymphoma is the fifth most common cancer in the world with an upsurge of incidence in India. Compared with Hodgkin disease, NHL is much less predictable and has a far greater predilection to disseminate to extranodal sites. Immunohistochemistry is a method for localising specific antigens in tissues or cells based on antigenantibody reaction. IHC is applied in three circumstances: to completely phenotype the abnormal population of cells, to further characterize the abnormal population identified by flow cytometry or to screen reactive tissue for a subtle abnormal population of cells. In the context of NHL, IHC is not only used in the aforementioned circumstances, but also to classify, sub-classify and predict prognosis. Since its discovery by Battifora in 1986, tissue microarray is becoming a useful tool for research and quality control in immunohistochemistry. Tissue microarray allows rapid and efficient analysis of large number of paraffin-embedded NHL tissues by a panel of markers under standardized immunohistochemical technique.

\section{Material and Methods}

This is the three year single institutional observational study conducted at Tirunelveli medical college, Tirunelveli, Tamilnadu. Ethical committee approval was taken prior to the study. Study material includes 21 cases of histopathologically diagnosed Non Hodgkin lymphoma in the Department of Pathology.

Inclusion Criteria: All the cases of Non-Hodgkin lymphoma that were diagnosed using Hematoxylin and Eosin stain, cases with a differential diagnosis of Non Hodgkin Lymphoma and cases where an IHC confirmation was requested.

Exclusion Criteria: [a] Inadequate lymph node sample, [b] Poorly processed material, [c] All cases of extra-nodal Non Hodgkin Lymphoma.

Methodology: The method of performing immunohistochemistry over the paraffin tissue microarray includes the following steps.

1. Designing the layout for TMA construction.

2. Collection of the donor blocks. 
3. Preparation of the recipient paraffin blocks.

4. Immunohistochemistry and analysis.

Designing the Lay Out: Before constructing the array proper, the layout of the tissue microarray defining the geometric position of each tissue core in the recipient block was made. The grid was constructed in such a way that there were minimum of two cores from each case and maximum of three cores on the recipient blocks except for two cases which had single representative core. All the cores from each case were placed in the same block in different positions. The grid was constructed in such a way that there were blank cores in between the cores from the cases which helped in determining the position of the cases on the immunohistochemistry performed slides.

Collection of the Donor Blocks: The hematoxylin and eosin stained sections which were prepared from formalin fixed paraffin embedded blocks of all the cases of NHL in the Department of pathology during the study period were retrieved. The corresponding formalin fixed paraffin embedded tissues were also obtained which constituted the donor block. Then the hematoxylin and eosin stained slides which contained full sections were examined and the area of interest containing well preserved and well stained malignant cells was marked by using black glass marking pen. Then these marked areas on the slides were matched with the donor blocks and the corresponding areas over the donor blocks were also marked with the help of black glass marking pen. This area was used as the site for obtaining cores for the recipient blocks.

Preparation of the Recipient Paraffin Blocks: The empty paraffin recipient blocks with minimum size of $25 \mathrm{~mm} \mathrm{x}$ $25 \mathrm{~mm}$ were first prepared by freshly poured molten wax in the metal moulds. Then it was allowed to cool. Later using 16gauge bone marrow aspiration needle, paraffin wax cylinders of $2 \mathrm{~mm}$ diameter were punched manually from the recipient blocks. Each block contained $3 \times 3$ cylinder matrix at a distance less than $2 \mathrm{~mm}$. Seven such blocks were prepared.

Then using 14gauge bone marrow aspiration needle, tissue cylinders were obtained from the area of interest which were previously marked over the donor blocks, after which it was injected into the recipient blocks into the corresponding empty cylinders with the help of predesigned layouts so that each recipient blocks contained three cases. After the recipient block was embedded with the tissue cores, the block was incubated at $40^{\circ} \mathrm{c}$ for 15 minutes and then it was allowed to cool for few minutes at room temperature and then the array was chilled on the ice for few minutes. Finally the 3-4microns sections were taken over the surface of the APES (3-aminopropyltriethoxysilane) coated slides using a microtome.
Immunohistochemistry: Sections were taken at 3-4microns thickness after tissue microarray construction along with a control section on the surface of the APES (3-aminopropyltriethoxysilane) coated slides. Immunohistochemistry was performed as per the manufacturer's instruction.

Grading of IHC stained sections Grading was done by following the method as opted by Afaf Abdel- Aziz, AbdelGhafar $^{[2)}$. First the tumour cells are observed for positive membrane/cytoplasmic staining pattern after which it is graded based upon the percentage of tumour cells which shows positive expression of antibody used as follows, No Reaction: 0.

Less than $5 \%$ of the tumour cells showing positive membranous/cytoplasmic expression: $1+$.

$5-9 \%$ of the tumour cells showing positive membranous/ cytoplasmic expression: $2+$.

$10-20 \%$ of the tumour cells showing positive membranous/ cytoplasmic expression: $3+$.

More than $20 \%$ of the tumour cells showing positive membranous/cytoplasmic expression: $4+$.

\section{Results}

Total of 21 cases of histopathologically diagnosed NHL were included in the study of which one was proven non malignant by IHC and one had tissue loss. Hence 19 cases were taken for analysis after immunohistochemistry. Among 19 cases, 11[57.89\%] were male and 8[42.11\%] were female with male to female ratio of $1.37: 1$. Age group of cases ranged from 11-78 years with mean age of 54.7 years. There were $18[94.73 \%]$ cases of B-cell NHL with $1[5.27 \%]$ case of T-cell NHL. Maximum number among B-cell NHL were Diffuse large B cell lymphoma constituting for $50 \%$ [9cases] of total B-cell NHL and $47.36 \%$ of total NHL.CLL/SLL/Mantle cell lymphoma constitutes for 6 cases [33.33\%], mantle cell lymphoma constitutes for 2 cases [11.11\%] with single case [5.5\%] of nodal marginal zone NHL. All of the 9 cases [100\%] of DLBCL showed diffuse pattern of staining with CD 20 and CD10, 5 cases [55.55\%] showed diffuse pattern of staining for CD5 and 3 cases [33.33\%] showed focal non specific staining for CD3. Out of the 6 cases of CLL/SLL / Mantle cell lymphoma, all of them showed diffuse pattern of staining for CD20 and CD5 and one case [16.66\%] showed focal staining in the interfollicular area with CD3. Out of the 2 cases of mantle cell lymphoma, one case [50\%] showed diffuse staining of CD20 and CD5 with focal staining in the follicular area with CD3 while the other 
showed diffuse staining with CD20 and focal follicular staining with CD 5. The single case of nodal marginal zone lymphoma showed diffuse staining pattern with CD20 and CD5 and interfollicular area was positively stained with CD3. The one case that was diagnosed as T cell lymphoma showed diffuse grade $2+$ positivity for CD3 and focal grade $2+$ positivity for CD5 while CD20 was negative. Out of the 9 cases of diffuse large B cell lymphoma, 5[55.55\%] of them showed grade 4+ membrane positivity, 2[22.22\%] of them showed grade $3+$ membrane positivity and one case $[11.11 \%]$ showed grade $1+$ membrane positivity with CD20. As far as CD10 was concerned in diffuse large B cell lymphoma cases, 2[22.22\%] of them showed grade2+ membrane positivity and the rest $[77.77 \%]$ had grade $1+$ membrane positivity. Out of the 6 cases of CLL/SLL / Mantle cell lymphoma, 3[50\%] cases showed grade 4+ membrane positivity, $2[33.33 \%]$ were grade $3+$ membrane positive and rest [16.66\%] showed grade $1+$ membrane positivity with CD20. As far as CD5 was concerned in CLL/SLL / Mantle cell lymphoma cases, 2[33.33\%] cases showed grade $3+$ and $3[50 \%]$ of them showed grade $2+$ membrane positivity while one case [16.66\%] showed grade $1+$ membrane positivity. Out of the single case of nodal marginal zone lymphoma there was grade $2+$ positivity for CD5, grade $4+$ positivity for CD20 and grade $1+$ positivity for CD3. Among mantle cell lymphoma cases, one [50\%] had grade $3+$ positivity for $\mathrm{CD} 20$ and grade $2+$ positivity for CD5 while the other had grade1+ for CD 20 and $3+$ for CD5.

Immunohistochemistry performed using conventional paraffin embedded tissue sections consumes 0.8 IU of primary antibody, secondary antibody and chromogen while IHC performed using manual tissue microarray consumed 0.13 IU of primary antibody, secondary antibody and chromogen. Hence IHC using manual tissue microarray uses $1 / 6^{\text {th }}$ of the reagent volume as that of IHC using standard tissue sections.

\section{Discussion}

The application of tissue microarray for the use of immunohistochemical diagnosis and classification of NHL has gained importance in the field of medical research for evaluation of prognosis and treatment modalities. Lynette $\mathrm{K}$ Tumwine ${ }^{[3]}$, in his study "Immunohistochemical and other prognostic factors in B cell NHL", at Kampala, Uganda used TMA for IHC analysis of NHL and studied prognostic factors in B cell lymphoma. According to Naresh KN $2000^{[4]}$, B cell lymphoma formed $79.1 \%$ of NHL, $72 \%$ according to Kalyan $\mathrm{K}$ et al, 2006 ${ }^{[5]}, 86 \%$ according to Mushtaq S et al ${ }^{[6]}, 2008$ and $96 \%$ according to Padhi S et al, 2012 ${ }^{[7]}$. In this study B-cell NHL constituted for $94.73 \%$ which correlates with above studies. According to K.E.Hunt and Reichard, $2008{ }^{[8]}$, diffuse B cell lymphomas are the most frequently occurring B cell Non Hodgkin lymphoma, worldwide. In two studies reported from Mumbai (India) in the year 2000 and 2011 ${ }^{[9]}$, DLBCL was found to be $34 \%$ and $42 \%$ respectively. In the present study DLBCL accounts for $50 \%$ which is similar to above studies. According to Jaffe $\mathrm{ES}^{([10]}$, mantle cell comprises about $2-10 \%$ of all Non-Hodgkin lymphoma. Roy et $\mathrm{a}^{[11]}$, through his study documented that mantle cell lymphoma ,marginal zone lymphoma and CLL/SLL constituted for $4 \%, 2.7 \%$ and $13 \%$ respectively. In the current study, cases which showed small cell morphology along with CD20 and CD5 positivity were categorised as CLL/SLL / Mantle

Table 1: Distribution of cases.

\begin{tabular}{|c|c|c|}
\hline Content & Number of cases & Percentage of cases \\
\hline Cases taken for analysis after IHC & 19 & $94.73 \%$ \\
\hline NHL of B-cell type & 18 & $5.27 \%$ \\
\hline NHL of T-cell type & 1 & $47.36 \%$ \\
\hline DLBCL & 9 & $31.57 \%$ \\
\hline CLL/SLL/Mantle cell NHL & 6 & $10.52 \%$ \\
\hline Mantle cell NHL & 2 & $5.27 \%$ \\
\hline
\end{tabular}

Table 2: Quantification of IHC reagents used in conventional against TMA sections.

\begin{tabular}{|c|c|c|c|}
\hline $\begin{array}{c}\text { Immunohistochemical } \\
\text { reagent }\end{array}$ & TMA & Conventional section & Consumption ratio \\
\hline Primary antibody & .13 IU & .8 IU & $1: 6$ \\
\hline Secondary antibody & .13 IU & .8 IU & $1: 6$ \\
\hline Chromogen & .13 IU & .8 IU & $1: 6$ \\
\hline
\end{tabular}




\begin{tabular}{|c|c|c|c|}
\hline \multirow{3}{*}{ BLOCK1 } & $1 \mathrm{~A} 1$ & $1 \mathrm{~A} 2$ & $1 \mathrm{~A} 3$ \\
\hline & $1 \mathrm{~B} 1$ & BLANK & 183 \\
\hline & $1 \mathrm{Cl}$ & $1 C 2$ & BLANK \\
\hline \multirow[t]{3}{*}{ BLOCK2 } & 2D1 & 2D2 & $2 \mathrm{D} 3$ \\
\hline & $2 \mathrm{E} 1$ & $2 E 2$ & BLANK \\
\hline & $2 \mathrm{~F} 1$ & $2 \mathrm{~F} 2$ & BLANK \\
\hline \multirow[t]{3}{*}{ BLOCK 3} & $3 G 1$ & $3 G 2$ & $3 \mathrm{G} 3$ \\
\hline & $3 \mathrm{H} 1$ & BLANK & $3 \mathrm{H} 3$ \\
\hline & BLANK & 112 & 313 \\
\hline \multirow[t]{3}{*}{ BLOCK4 } & $4 J 1$ & $4 J 2$ & 4J 3 \\
\hline & BLANK & $4 K 2$ & BLANK \\
\hline & $4 \mathrm{~L} 1$ & BLANK & $4 L 3$ \\
\hline \multirow[t]{3}{*}{ BLOCK5 } & $5 \mathrm{MI}$ & $5 \mathrm{M} 2$ & $5 \mathrm{M3}$ \\
\hline & $5 N 1$ & BLANK & $5 N 3$ \\
\hline & 501 & 502 & BLANK \\
\hline \multirow[t]{3}{*}{ BLOCK6 } & 6P1 & $6 P 2$ & $6 P 3$ \\
\hline & $6 Q 1$ & $6 Q 2$ & BLANK \\
\hline & 6R1 & BLANK & $6 \mathrm{R} 3$ \\
\hline \multirow[t]{3}{*}{ BLOCK7 } & BLANK & 752 & 753 \\
\hline & 7T1 & BLANK & $7 T 3$ \\
\hline & $7 \cup 1$ & BLANK & BLANK \\
\hline
\end{tabular}

Fig. 1: Tissue microarray Layout.

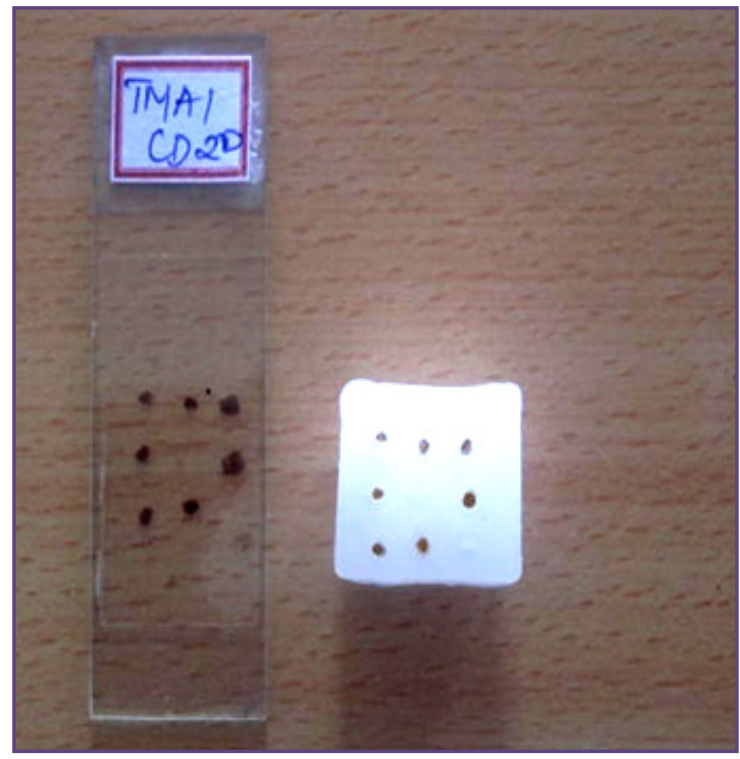

Fig. 2: Tissue microarray paraffin tissue block along with slide after performing immunohistochemistry. 


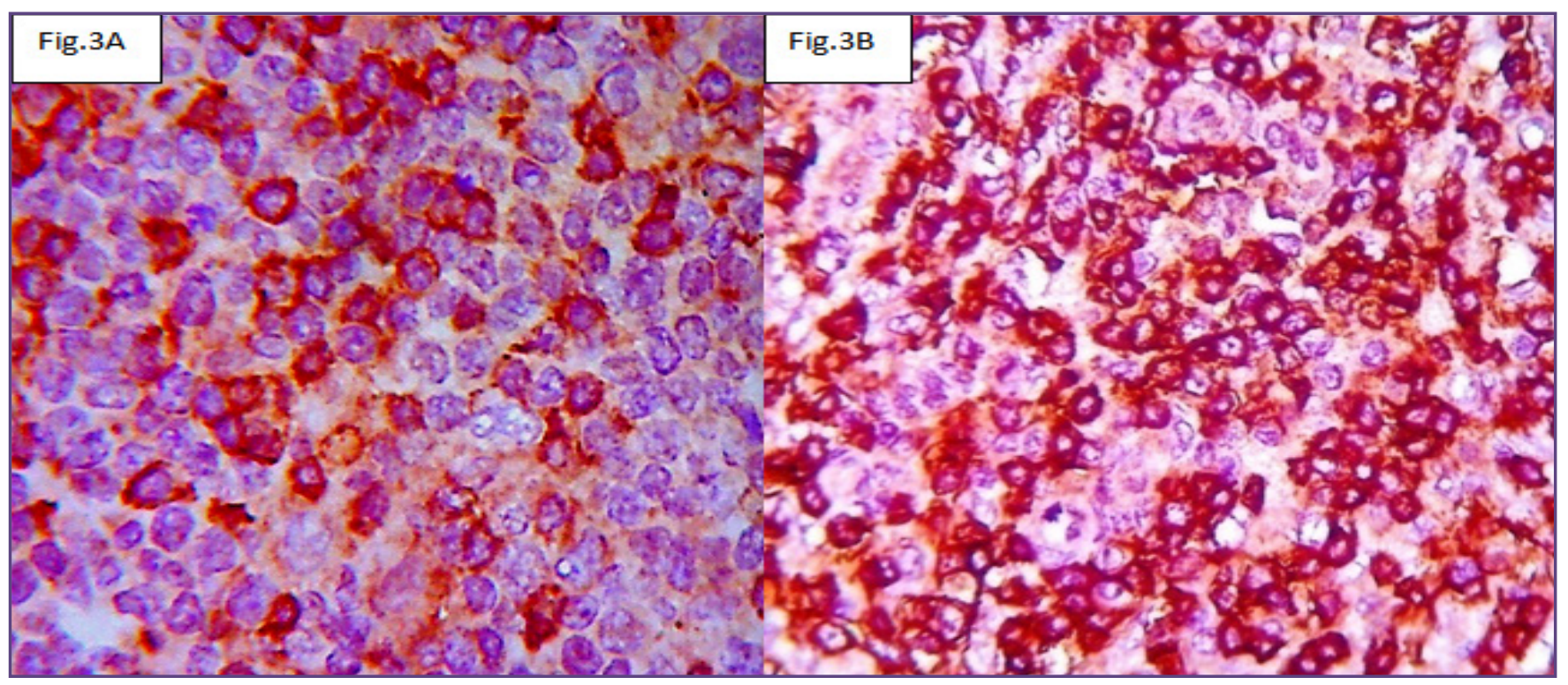

Fig.3: A- A case of diffuse large B-cell lymphoma showingdifffuse positive membrane expression for CD 20 [IHC, $400 \mathrm{X}$ ]; B-A case of CLL/SLL/Mantle cell NHL showing diffuse positive membrane expression for CD 5 [IHC, 400X].

cell lymphoma but further classification was not done due to non availability of cyclinD1. This constituted $33.33 \%$. Two cases of mantle cell lymphoma were diagnosed, correlating with cell morphology, immunohistochemistry and one case was associated with lymphomatous polyposis in the ileum. Mantle cell lymphoma accounted for $11.11 \%$ and nodal marginal zone lymphoma accounted for $5.5 \%$ of cases. According to Picker $\mathrm{LJ}^{[12]}$, all the cases of diffuse large B-cell lymphoma expresses CD20 and Fang JM et $\mathrm{al}^{[13]}$ through his study found that $20-30 \%$ of the cases of DLBCL are positive for CD10 which correlates with the present study. Watson et al ${ }^{[14]}$, Kurtin $\mathrm{PJ}{ }^{[15]}$ and Campo $\mathrm{E}^{[16]}$ found that most cases of nodal marginal zone lymphomas show positive expression for CD20 with negative expression of CD3, CD5, CD10. In the current study, the case which showed monotonous lymphoid cell proliferation with marginal zone expansion histomorphologically with positive membrane expression for CD20, CD5 and CD3 was diagnosed as nodal marginal zone lymphoma. The result obtained differed from the above studies. According to Mucci NR et al ${ }^{[17]}$, Schrami et $\mathrm{a}^{\left[{ }^{[18]}\right.}$ and Richter $\mathrm{J}$ et $\mathrm{a}^{\left[{ }^{19]}\right.}$ tissue loss may be significant using tissue micro array with rate of tissue damage ranging from $15-33 \%$. Hager $M$ et al in his study on renal cell carcinoma using tissue micro array observed tissue loss due to technical problems which accounted for $23 \%$. In the present study tissue loss was found among one case during the procedure which accounts for $4.76 \%$. This may be attributed to small core depth, improper embedding, faulty section cutting, and improper antigen retrieval technique. These can be overcome by following standard protocols and obtaining more number of tissue cores especially triplicate cores from the donor block. The use of chemicals for performing IHC is critical using tissue micro array. We used insulin syringe for dispersal of primary antibody, secondary antibody and DAB chromogen. To analyse single conventional tissue section immunohistochemically, minimum of two drops $(0.8 \mathrm{IU})$ of chemical reagents which includes primary antibody, secondary antibody and DAB chromogen are required. $1 \mathrm{ml}$ insulin syringe can hold 40IU of the reagent which equals 100 drops. Hence, a single tissue section when used conventionally consumes $0.8 \mathrm{IU}$ of the reagent whereas in TMA, the same quantity has been used to analyze 6 cores taken from three different cases. So TMA, apart from having the advantage of parallel analysis of multiple sections also decreases the time taken for the IHC procedure and the amount of chemical reagents used. Furthermore, the use of immunohistochemical analysis in NHL by tissue microarray is helpful in comparative analysis of the tumor, sub-classification which is essential for determining treatment, prognosis and standardisation of the chemical reagents.

\section{Conclusion}

Among 19 cases taken for analysis after IHC, B-cell NHL formed the bulk with DLBCL constituting for maximum number of cases. Application of a basic required panel of markers for immunophenotyping of the Non Hodgkin Lymphoma aid in the sub-classification and could modify the therapeutic modalities, thereby prognosis. The process of immunohistochemistry using conventional tissue section consumes more reagents, also require control 
and standardization for each batch when compared to tissue microarray. By taking representative cores from different cases and performing IHC on them on a single slide not only proved to be economical but also aided in the standardisation of the reagents and procedure. Hence using a basic panel of markers for immunohistochemistry on tissue microarray saves time, cost and aids in precise tissue diagnosis.

\section{Abbreviations and Symbols}

APES-Aminopropyltriethoxysilane, CD-Cluster of differentiation, CLL-Chronic lymphocytic lymphoma, DLBCL-Diffuse large B-cell lymphoma, EDTA-Ethylene diamine tetracetic acid, IHC-Immunohistochemistry, NHL-Non Hodgkin lymphoma, NK-Natural killer, SLLSmall lymphocytic lymphoma, TMA-Tissue micro array.

\section{Acknowledgement}

I would like to thank Ethical committee of our Institution and my Guide DR. SURESH DURAI M.D for approving my study, my family members and friends for their support.

\section{References}

1. Rao SI. Role of immunohistochemistry in lymphoma. Indian Journal of Medical and Paediatric Oncology. 2010;31(4):145-147.

2. Afaf Abdel-Aziz Abdel-Ghafar, Manal Ahmed Shams El Din El Telbany, Hanan Mohamed

3. Mahmoud, Yasmin Nabil El-Sakhawy. Immunophenotyping of chronic B-cell neoplasms: flow cytometry versus immunohistochemistry. Hematology reports. 2012;4(1):e3.

4. Tumwine LK, Agostinelli C, Campidelli C, et al. Immunohistochemical and other prognostic factors in B cell non Hodgkin lymphoma patients, Kampala, Uganda. BMC Clinical Pathology. 2009;9(11).

5. Naresh KN, Srinivas V, Soman CS. Distribution of various subtypes of non-Hodgkin's lymphoma in India: a study of 2773 lymphomas using R.E.A.L. and WHO Classifications. Ann Oncol. 2000;11(Suppl 1):63-67.

6. Kalyan K, Basu D, Soundararaghavan J. Immunohistochemical typing of non Hodgkin'slymphomacomparing working formulation and WHO classification. Indian J Pathol Microbiol. 2006Apr ; 49(2):203-7.

7. Mushtaq S, Akhtar N, Jamal S, et al. Malignant lymphomas in Pakistan according to the WHO classification of lymphoid neoplasms. Asian Pac J Cancer Prev. 2008AprJun;9(2):229-232.
8. Padhi S, Paul TR, Challa S, et al. Primary Extra Nodal Non Hodgkin Lymphoma: A 5 Year Retrospective Analysis. Asian Pac J Cancer Prev. 2012;13(10):4889-4895.

9. Hunt KE, Reichard, KK. Diffuse large B-cell lymphoma. Arch Pathol Lab Med. 2008; 132(1):118-124.

10. Sengar M, Akhade A, Nair R, et al. A retrospective audit of clinicopathological attributes and treatment outcomes of adolescent and young adult non-Hodgkin lymphomas from a tertiary care center. Indian Journal of Medical and Paediatric Oncology. 2011;32:197-203.

11. Jaffe ES. Hematopathology: integration of morphologic features and biologic markers for diagnosis. Mod Pathol. 1999;12(2):109-115.

12. Roy A, Kar R, Basu D, Badhe BA. Spectrum of histopathologic diagnosis of lymph node biopsies: A descriptive study from a tertiary care center in South India over 51/2 years. Indian J Pathol Microbiol. 2013;56;103-108.

13. Picker LJ, Weiss LM, Medeiros LJ, Wood GS, Warnke RA. Immunophenotypic criteria for the diagnosis of nonHodgkin's lymphoma. Am J Pathol. 1987;128(1):181-201.

14. Fang JM, Finn WG, Hussong JW, Goolsby CL, Cubbon AR, Variakojis D. CD10 antigen expression correlates with the $\mathrm{t}(14 ; 18)(\mathrm{q} 32 ; \mathrm{q} 21)$ major breakpoint region in diffuse large B-cell lymphoma. Mod Pathol. 1999;12:295-300.

15. Watson P, Wood KM, Lodge A, et al. Monoclonal antibodies recognizing CD5, CD10 and $\mathrm{CD} 23$ in formalin-fixed, paraffin embedded tissue: production and assessment of their value in the diagnosis of small B-cell lymphoma. Histopathology. 2000;36(2):145-150.

16. Kurtin PJ, Hobday KS, Ziesmer S, Caron BL. Demonstration of distinct antigenic profiles of small B-cell lymphomas by paraffin section immunohistochemistry. Am J Clin Pathol. 1999;112(3):319-329.

17. Campo E, Miquel R, Krenacs L, Sorbara L, Raffeld M, Jaffe ES. Primary nodal marginal zone lymphomas of splenic and MALT type. Am J Surg Pathol. 1999 Jan;23(1):59-68.

18. Mucci NR, Akdas G, Manely S, Rubin MA. Neuroendocrine expression in metastatic prostatic cancer: evaluation of high throughput tissue microarrays to detect heterogenous protein expression. Hum Pathol. 2000;31(4):406-414.

19. Schraml P, Kononen J, Bubendorf L, et al. Tissue microarrays for gene amplification surveys in many different tumors types. Clin cancer Res. 1999;5(8):1966-75.

20. Richter J, Wagner U, Kononen J, et al. High-throughput tissue microarray analysis of cyclin E gene amplification and overexpression in urinary bladder cancer. Am J Pathol. 2000;157(3):787-794.

*Corresponding author:

Dr. Anbu Lenin Kulandaivel, 24, Visalakshi Apartments, S5, Third Floor, Gandhi Road, Salem -636 007, Tamil Nadu, India. Phone: +91 9944243745

Email: dranbulenin@gmail.com

Financial or other Competing Interests: None. 